\begin{tabular}{|c|l|}
\hline Title & $\begin{array}{l}\text { Preparation and Reaction of Titania Particles Encapsul ated in Hollow Silica Shells as an Efficient Photocatalyst for } \\
\text { Stereoselective Synthesis of Pipecolinic A cid }\end{array}$ \\
\hline Author(s) & Chandren, Sheela; Ohtani, Bunsho \\
\hline Citation & $\begin{array}{l}\text { Chemistry Letters, 41/7), 677-679 } \\
\text { https://doi.org/40.1246/1.2012.677 }\end{array}$ \\
\hline Issue Date & 2012-07 \\
\hline Doc URL & http://hdl.handle.net/2115/52960 \\
\hline Type & article (author version) \\
\hline File Information & CL41-7_677-679.pdf \\
\hline
\end{tabular}

Instructions for use 


\title{
Preparation and Reaction of Titania Particles Encapsulated in Hollow Silica Shells as an Efficient Photocatalyst for Stereoselective Synthesis of Pipecolinic Acid
}

\author{
Sheela Chandren ${ }^{1,2}$ and Bunsho Ohtani*1 \\ ${ }^{1}$ Catalysis Research Center, Hokkaido University, Sapporo 001-0021, Japan \\ ${ }^{2}$ Asian Graduate School of Chemistry and Material Science (Graduate School of Engineering), Hokkaido University, Sapporo 060-8628, \\ Japan
}

(Received <Month $><$ Date $>,<$ Year $>$; CL-<No $>$; E-mail: ohtani@ cat.hokudai.ac.jp

Hollow core-shell particles of titania core and silica shell were synthesized by multistep process, and the core-shell particles showed improved stereoselectivity in the photocatalytic redox-combined synthesis of L-pipecolinic acid from L-lysine in an aqueous suspension without reducing the original activity of the bare titania core.

Photocatalytic reactions occurring on the surface of photoirradiated titania $\left(\mathrm{TiO}_{2}\right)$ have garnered a wide interest due to their potential environmental applications. ${ }^{1,2}$ An example is photoinduced removal of chemical contaminants under atmospheric conditions, being attributed to the ability of $\mathrm{TiO}_{2}$ photocatalyst to cleave chemical bonds nonselectively, i.e., mineralization. However, selective reactions of targeted chemicals are also possible. One of the most useful approaches for selective photocatalytic reaction is operation of a photocatalytic reaction under deaerated conditions where undesirable excessive oxidation through the radical chain reaction with oxygen $\left(\mathrm{O}_{2}\right)$ is prohibited and thereby an alternative electron acceptor should be used. ${ }^{3,4}$ Another approach for the selective organic synthesis is utilization of photocatalysts of or in defined microstructures; $\mathrm{TiO}_{2}$ particles or isolated titanium oxide species are distributed onto or into inorganic supports. ${ }^{5,6}$ According to previous works, ${ }^{7,8}$ one of the most widely used methods to provide the selectivity is encapsulation of $\mathrm{TiO}_{2}$ particles into porous substances. However, the surface coverage of these substances causes decrease in intrinsic photocatalytic activity of the medial $\mathrm{TiO}_{2}$.

We have reported ${ }^{9,10}$ fabrication of a novel core-shell composite photocatalyst which consisted of commercially available $\mathrm{TiO}_{2}$ particles incorporated in a hollow silica shell $\left(\mathrm{SiO}_{2} /\right.$ void/TiO $\left.{ }_{2}\right)$. The composite possesses size-selective properties in the photodecomposition of organic compounds; $\mathrm{SiO}_{2} /$ void $/ \mathrm{TiO}_{2}$ showed photocatalytic activity for decomposition of small substrates retaining the activity of original bare $\mathrm{TiO}_{2}$, while negligible activity for polymers was observed, i.e., $\mathrm{SiO}_{2} /$ void $/ \mathrm{TiO}_{2}$ exhibits molecular size selectivity. Recently, we have attempted to use the $\mathrm{SiO}_{2} /$ void/TiO $/ \mathrm{T}_{2}$ photocatalyst for the synthesis of Lpipecolinic acid (L-PCA), a useful intermediate material for various fine chemicals, ${ }^{11}$ and found another function of silica shell to improve stereoselectivity, instead of molecular-size selectivity and report here.

Preparation of $\mathrm{SiO}_{2} /$ void $/ \mathrm{TiO}_{2}$ was performed by coating of $\mathrm{TiO}_{2}$ with a carbon layer and a silica layer followed by heat treatment to remove the carbon layer, ${ }^{9}$ as shown schematically in Fig. 1(a) (For details, see SI). An SEM image of source $\mathrm{TiO}_{2}$ core (Ishihara Sangyo ST-41) is shown in Fig. 1(b). An angular morphology of the sample was distinctly observed. The particle size was in the range of $100-300 \mathrm{~nm}$. The $\mathrm{TiO}_{2}$ powder was treated with 3-aminopropyltrimethoxysilane (APS) and the APSmodified $\mathrm{TiO}_{2}$ was then subjected to hydrothermal reaction in an aqueous glucose at $180{ }^{\circ} \mathrm{C}$ for $6 \mathrm{~h}$. The resulting polysaccharide (PS)-covered particles were recovered and heated at $600{ }^{\circ} \mathrm{C}$ under vacuum for $2 \mathrm{~h}$. This resulted in the encapsulation of the particle aggregates with a thick uniform layer of carbon $\left(\mathrm{C} / \mathrm{TiO}_{2}\right)$. The thickness of layer was $30-80 \mathrm{~nm}$. Then, $\mathrm{C} / \mathrm{TiO}_{2}$ was treated with $n$-(2aminoethyl)-3-aminopropyltrimethoxysilane and then with tetraethyl orthosilicate (TEOS) followed by heat treatment under vacuum at $600{ }^{\circ} \mathrm{C}$ to obtain $\mathrm{TiO}_{2}$ particles covered with a carbon layer and a silica layer $\left(\mathrm{SiO}_{2}\right.$ (silylation time $/ \mathrm{h}) / \mathrm{C} / \mathrm{TiO}_{2}$ ). Finally, the carbon layer was removed by calcinations at $600{ }^{\circ} \mathrm{C}$ for $2 \mathrm{~h}$ in air, thus successfully yielding $\mathrm{TiO}_{2}$ encapsulated in a hollow silica shell $\left(\mathrm{SiO}_{2} /\right.$ void/TiO 2 ). SEM images in transmission mode (Fig. 1(c)) showed the presence of void space of 3-10 nm in width between shell of around $9-10 \mathrm{~nm}$ in thickness and core $\mathrm{TiO}_{2}$ particles for $\mathrm{SiO}_{2}(0.5) /$ void/TiO 2 . The presence of void space was also supported by the fact that specific surface area (BET method) of $\mathrm{SiO}_{2} /$ void/TiO $2\left(29 \mathrm{~m}^{2} \mathrm{~g}^{-1}\right)$ was more than twice higher than that of the original $\mathrm{TiO}_{2}$ $\left(13 \mathrm{~m}^{2} \mathrm{~g}^{-1}\right)$. As a reference, $\mathrm{TiO}_{2}$ mechanically mixed with silica $\left(m e c-\mathrm{SiO}_{2}+\mathrm{TiO}_{2}\right)$ and $\mathrm{TiO}_{2}$ directly coated with silica ( dir- $-\mathrm{SiO}_{2} / \mathrm{TiO}_{2}$ ) were also prepared, the latter of which was prepared according to the procedures by Graf et al. ${ }^{12}$ with slight modification (For details, see SI).

Since platinum (Pt) deposits on the $\mathrm{TiO}_{2}$ surface are required for the photocatalytic synthesis of L-PCA, ${ }^{13}$ all samples were platinized $(2 \mathrm{wt} \%)$ using two-step photodeposition method. First, a sample was suspended in water containing required amount of hydrogen hexachloroplatinate(IV) $\left(\mathrm{H}_{2} \mathrm{PtCl}_{6} \cdot 6 \mathrm{H}_{2} \mathrm{O}\right)$ and irradiated by a $400-\mathrm{W}$ mercury arc (Eiko-sha 400 ; ca. $25 \mathrm{~mW} \mathrm{~cm}^{-2}$ at 300 $400 \mathrm{~nm}$ ) for $1.5 \mathrm{~h}$, and then irradiated for an additional $1.5 \mathrm{~h}$ in the presence of $50 \mathrm{vol} \%$ methanol.

Figure 2 shows the time-course curves of hydrogen $\left(\mathrm{H}_{2}\right)$ liberation from aqueous methanol solutions in the second step of the platinization. Almost linear increase in the amount of $\mathrm{H}_{2}$ was observed after some induction period for all the samples except for $\operatorname{dir}-\mathrm{SiO}_{2} / \mathrm{TiO}_{2}$, suggesting that reduction of platinum complex to metallic state, to induce methanol dehydrogenation, required 5-10 min irradiation. As shown in this figure, $\operatorname{dir}-\mathrm{SiO}_{2} / \mathrm{TiO}_{2}$ was almost inactive with negligible $\mathrm{H}_{2}$ liberation possibly due to retardation of adsorption of substrates, methanol and $\mathrm{H}_{2} \mathrm{PtCl}_{6}$, participating 
(a)

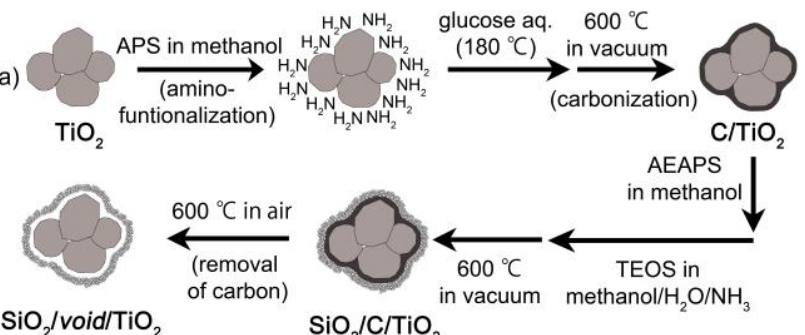

(b)

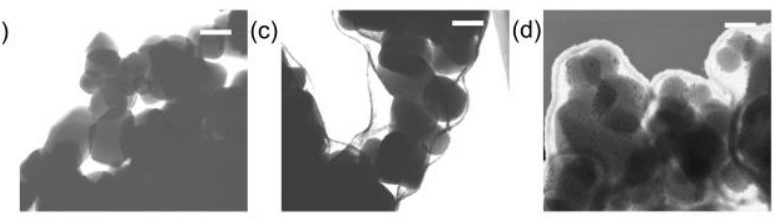

Figure 1. (a) Schematic representation of the procedure for preparation of $\mathrm{SiO}_{2} /$ void/TiO $\mathrm{T}_{2}$, SEM image taken in transmission mode for (b) $\mathrm{TiO}_{2}$, (c) $\mathrm{SiO}_{2}(0.5) /$ void/TiO and (d) $\mathrm{SiO}_{2}(0.5) /$ void/ $/ \mathrm{TiO}_{2}$ after deposition of Pt particles. Scale bar corresponds to $100 \mathrm{~nm}$.

in the reaction onto the $\mathrm{TiO}_{2}$ surface by the covering silica layer to result in practically no $\mathrm{Pt}$ deposition. The activity of $\mathrm{SiO}_{2} /$ void/TiO 2 was almost the same as that of bare $\mathrm{TiO}_{2}$ despite the presence of silica shell and even higher than that of $m e c-\mathrm{SiO}_{2}+\mathrm{TiO}_{2}$. SEM observation of the sample after the platinization process shown in Fig. 1(d) clearly indicating the deposition of fine $\mathrm{Pt}$ particles onto $\mathrm{TiO}_{2}$ without any collapse of the silica shells. The similar finding was observed in our previous research and this can be attributed to the presence of pores in silica shell and void spaces between the shell and core $\mathrm{TiO}_{2}$ particles. ${ }^{10}$ These structures led to efficient mass transfers through a silica shell to supply substrates that participate in this reaction to the naked active surface of the $\mathrm{TiO}_{2}$ core.

For the photocatalytic reaction of redox-combined stereoselective synthesis of L-pipecolinic acid (L-PCA) from L-lysine (L-Lys), a Pt-loaded photocatalyst $\left(0.05 \mathrm{~g}\right.$ as $\left.\mathrm{TiO}_{2}\right)$ was suspended in an aqueous solution $\left(5.0 \mathrm{~cm}^{3}\right)$ containing LLys $(100 \mu \mathrm{mol})$ and photoirradiated by a high-pressure mercury arc (Eiko-sha, $400 \mathrm{~W}$ ) under argon (Ar) under magnetic stirring $(1000 \mathrm{rpm})$. The photoirradiation was performed through a cylindrical Pyrex glass filter and a glass reaction tube $(18 \mathrm{~mm}$ in diameter and $180 \mathrm{~mm}$ in length) so that light of wavelength $>290 \mathrm{~nm}$ reached the suspension. The temperature of the suspension during photoirradiation was maintained at $25 \pm 0.5^{\circ} \mathrm{C}$ by the use of a thermostated water bath. After irradiation for $2 \mathrm{~h}$, a portion $\left(0.2 \mathrm{~cm}^{3}\right)$ of the gas phase of the sample was withdrawn with a syringe and subjected to gas chromatographic analysis (GC, Shimadzu GC-8A with an MS-5A column and a TCD detector) for $\mathrm{H}_{2}$. The yield of enantiomers of PCA, as well as the amount of unreacted L-Lys, was measured by HPLC (Shimadzu LC-6A equipped with a Daicel Chiral-Pak MA(+) column and an ultraviolet absorption detector).

Table 1 summarizes the results for the synthesis of LPCA from L-Lys by 2-h photoirradiation using various platinized $\mathrm{TiO}_{2}$ photocatalysts. Photoirradiation of the $\mathrm{TiO}_{2}$ photocatalysts suspended in an aqueous solution of L-Lys under $\mathrm{Ar}$ led to the formation of PCA, as reported previously. ${ }^{14,15}$ Complete consumption of L-Lys was

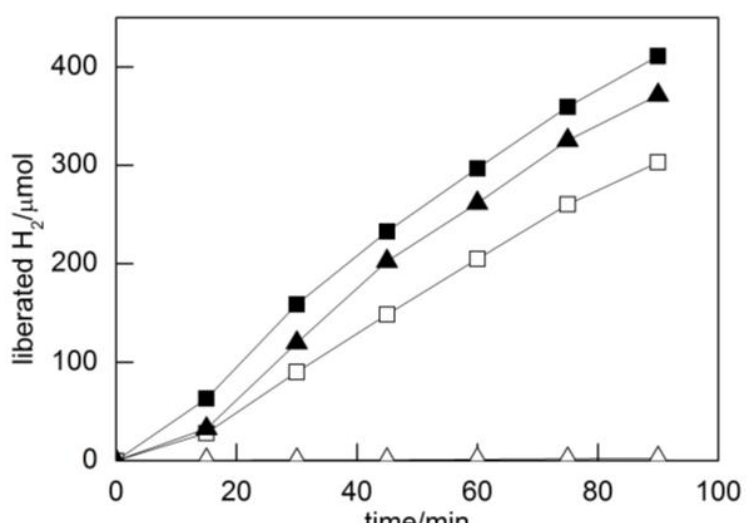

Figure 2. Time-course curves of $\mathrm{H}_{2}$ liberated from aqueous methanol solutions by $\mathrm{TiO}_{2}$ (filled squares), $\mathrm{SiO}_{2}(0.5) /$ void $/ \mathrm{TiO}_{2}$ (filled triangles), mec-SiO$+\mathrm{TiO}_{2}$ (open squares) and $\operatorname{dir}-\mathrm{SiO}_{2} / \mathrm{TiO}_{2}$ (open triangles) preirradiated in aqueous $\mathrm{H}_{2} \mathrm{PtCl}_{6}$ solutions.

Table 1. Synthesis of PCA from L-Lys using various platinized $\mathrm{TiO}_{2}$ photocatalysts.

\begin{tabular}{|c|c|c|c|c|c|}
\hline photocatalyst & $\begin{array}{l}\text { conver- } \\
\text { sion }(\%)\end{array}$ & $\begin{array}{c}\mathrm{S}_{\mathrm{PCA}}{ }^{\mathrm{a}} \\
(\%)\end{array}$ & $\begin{array}{c}\mathrm{OP}_{\mathrm{PCA}}{ }^{\mathrm{b}} \\
(\%)\end{array}$ & $\mathrm{R}_{\mathrm{PCA}}{ }^{\mathrm{c}}$ & $\begin{array}{c}\mathrm{Y}_{\mathrm{H} 2}{ }^{\mathrm{d}} \\
/ \mu \mathrm{mol}\end{array}$ \\
\hline $\mathrm{TiO}_{2}$ & 100 & 51 & 57 & 27 & 75 \\
\hline$m e c-\mathrm{SiO}_{2}+\mathrm{TiO}_{2}$ & 100 & 52 & 59 & 27 & 63 \\
\hline$d i r-\mathrm{SiO}_{2} / \mathrm{TiO}_{2}{ }^{\mathrm{e}}$ & 14 & 26 & $-f^{f}$ & 0.2 & 2 \\
\hline $\mathrm{SiO}_{2}(0.5) /$ void $/ \mathrm{TiO}_{2}$ & 98 & 43 & 70 & 22 & 72 \\
\hline $\mathrm{SiO}_{2}(1.5) /$ void $/ \mathrm{TiO}_{2}$ & 96 & 50 & 70 & 25 & 50 \\
\hline $\mathrm{SiO}_{2}(3.0) /$ void $/ \mathrm{TiO}_{2}$ & 96 & 46 & 70 & 23 & 57 \\
\hline
\end{tabular}

${ }^{\mathrm{a}}$ Selectivity of PCA production based on amount of consumed L-Lys. ${ }^{b}$ Optical purity of L-PCA. ${ }^{\mathrm{c}}$ Rate of PCA formation in the unit of $\mu \mathrm{mol}$ $\mathrm{h}^{-1}$. ${ }^{\mathrm{d}}$ Yield of $\mathrm{H}_{2}$. ${ }^{\text {ePlatinization via photodeposition was unsuccessful }}$ (see text). ${ }^{\mathrm{f}}$ Not determined.

achieved using $\mathrm{TiO}_{2}$ and also mec- $\mathrm{SiO}_{2}+\mathrm{TiO}_{2}$. These photocatalysts showed very similar results in terms of selectivity $\left(\mathrm{S}_{\mathrm{PCA}}\right)$, optical purity $\left(\mathrm{OP}_{\mathrm{PCA}}\right)$ and the rate of PCA formation $\left(\mathrm{R}_{\mathrm{PCA}}\right)$, suggesting that the mechanical mixing of silica with $\mathrm{TiO}_{2}$ does not give any effect on this reaction as only the $\mathrm{TiO}_{2}$ part was responsible for the photocatalytic reaction. As expected, $\operatorname{dir}-\mathrm{SiO}_{2} / \mathrm{TiO}_{2}$ showed poor photocatalytic activity to convert only $14 \%$ of L-Lys, thus proving that direct coverage of the $\mathrm{TiO}_{2}$ surface with silica hinders the activity of the $\mathrm{TiO}_{2}$ by prohibiting $\mathrm{Pt}$ deposition as well as L-Lys adsorption onto the bare $\mathrm{TiO}_{2}$ surface. The $\mathrm{SiO}_{2}(0.5) / \mathrm{void} / \mathrm{TiO}_{2}$ particles prepared with $0.5 \mathrm{~h}$ of silylation period showed the performance almost the same as that of bare $\mathrm{TiO}_{2}$. Although the selectivity was slightly lower than that of bare $\mathrm{TiO}_{2}, \mathrm{SiO}_{2} /$ void/TiO 2 exhibited the highest $\mathrm{OP}_{\mathrm{PCA}}$, $13 \%$ more than that of platinized bare $\mathrm{TiO}_{2}$, among all the samples. In order to further prove the effectiveness of the hollow core-shell structure, $\mathrm{SiO}_{2} /$ void/TiO ${ }_{2}$ with thicker layer of silica shell were also prepared, by extending the silylation period $(1.5 \mathrm{~h}$ and $3.0 \mathrm{~h})$. The thickness of the silica layer was increased to $14-32 \mathrm{~nm}$ and $28-45 \mathrm{~nm}$, respectively, from 9-

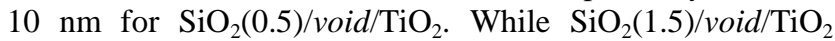
exhibited the best performance among the tested samples, it seemed that the photocatalytic performance (conversion, $\mathrm{S}_{\mathrm{PCA}}$, $\mathrm{OP}_{\mathrm{PCA}}$ and $\mathrm{R}_{\mathrm{PCA}}$ ) was almost independent of the silica shell thickness. This suggests that the silica shell behaves as highly porous optically transparent penetration-free layer which 


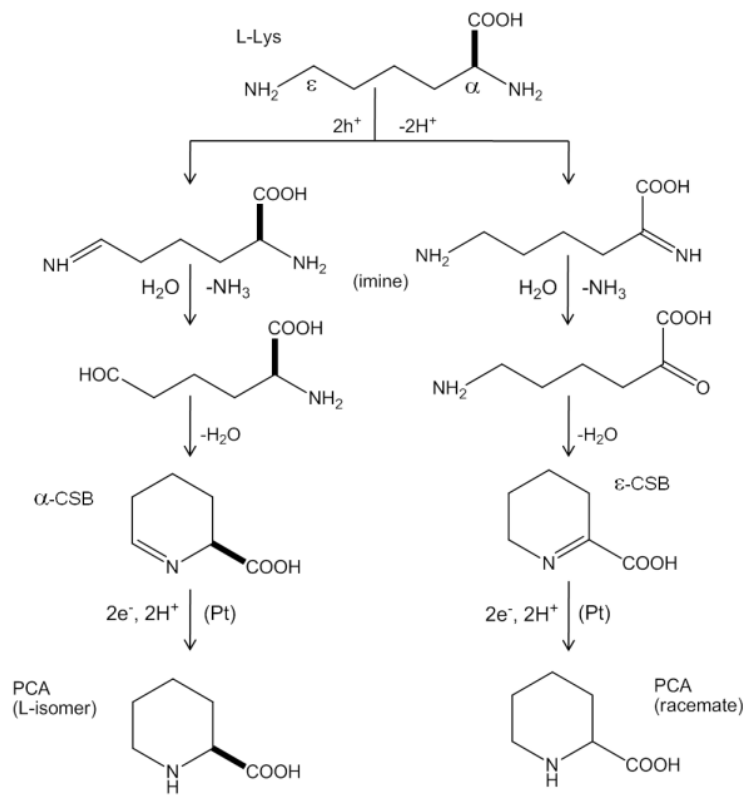

Scheme 1. Proposed mechanism of the photocatalytic $\mathrm{N}$-cyclization of L-Lys on platinized $\mathrm{TiO}_{2}$ photocatalysts.

surrounds the $\mathrm{TiO}_{2}$ core and that this swollen sponge-like silica layer controls the stereoselectivity of the reaction.

It has been proposed that PCA formation from L-Lys proceeds through redox-combined mechanism shown in Scheme $1:{ }^{16}$ one of the amino groups in L-Lys is oxidized by positive holes $\left(\mathrm{h}^{+}\right)$to imines, which are then hydrolyzed to an aldehyde or keto acid by $\varepsilon$ and $\alpha$-amino group oxidation, respectively, and then cyclic Schiff base (CSB) intermediates formed by intramolecular condensation are reduced by photoexcited electrons ( $\mathrm{e}^{-}$) to yield PCA. According to this mechanism, $\mathrm{OP}_{\mathrm{PCA}}$ is regulated by (1) selectivity in the position in the first oxidation process and (2) difference in efficiency in the following second process of conversion of from imine into PCA between $\varepsilon$ and $\alpha$-routes; $S_{\mathrm{PCA}}$ corresponds to the average efficiency of the second process. On the assumption of same efficiency in the second process for $\alpha$ and $\varepsilon$-routes, $\mathrm{OP}_{\mathrm{PCA}}$ shows proportion of the $\varepsilon$-route, since $\varepsilon$ and $\alpha$-routes yield $\mathrm{L}$ and racemic PCA, respectively. A possible reason for improved $\mathrm{OP}_{\mathrm{PCA}}$, with almost the same $\mathrm{S}_{\mathrm{PCA}}$, by the use of $\mathrm{SiO}_{2} /$ void/TiO 2 is increase in the proportion of $\varepsilon$-route, presumably due to acidic property of silica. ${ }^{17}$ It has been observed that operation of the reaction at lower $\mathrm{pH}$ improved $\mathrm{OP}_{\mathrm{PCA}}$ and decreased $\mathrm{R}_{\mathrm{PCA}}$ when platinized (bare) $\mathrm{TiO}_{2}$ particles were used as a photocatalyst. ${ }^{18}$ Since $\varepsilon$-amino group is protonated to be ammonium group ($\mathrm{NH}_{3}{ }^{+}$), compensating negative charge of carboxylate and leaving $\alpha$-amino group in neutral form under the conditions employed in this study, ${ }^{19}$ preferential oxidation of $\varepsilon$-amino group cannot be expected with ordinary photocatalyst particles. Possible acidic microenvironment of the core $\mathrm{TiO}_{2}$ surface induced by silica shell might lead to protonation of $\alpha$ amino group to result in the retardation of $\alpha$-route due to higher (more anodic) oxidation potential of ammonium form of amino groups. As reported previously, ${ }^{15}$ blocking of $\varepsilon^{-}$ amino group by carbamoyl derivatization not to be protonated and thereby preferential protonation of $\alpha$-amino group in Lys led to the production of optically pure L-PCA. Preliminary study on acid properties of samples by ammonia TPD
(Belsorp, Bel Japan) suggested the presence of small amount of weak acid sites (desorption at $150-300^{\circ} \mathrm{C}$; ca. $1 \mu \mathrm{mol} \mathrm{g}{ }^{-1}$ in total) presumably due to the $\mathrm{SiO}_{2}$ layer. Measurements of the L-Lys adsorption and acid properties through ammonia TPD and zeta-potential analysis are under study.

In conclusion, the present hollow core-shell structured photocatalyst provides the improved $\mathrm{OP}_{\mathrm{PCA}}$ keeping the $\mathrm{S}_{\mathrm{PCA}}$ and $\mathrm{R}_{\mathrm{PCA}}$ without addition of any chemicals, such as an acid or a buffer solution, which must be separated in the post reaction procedure. Though improved $\mathrm{OP}_{\mathrm{PCA}}$ was still not so high $(70 \%)$, this enables purification of L-PCA by recrystallization. ${ }^{15}$ It is expected that modification of silica with more acidic functional groups and/or choice of appropriate thickness of void space between core and shell improve the performance of photocatalysts for stereoselective synthesis of L-PCA, and study along this line is now in progress.

\section{Acknowledgments}

The authors thank Professors Wataru Ueda and Toru Murayama (Hokkaido University) for their help in ammonia TPD analysis. Professor Shigeru Ikeda (Osaka University) is gratefully acknowledged for his advice on sample preparation.

\section{References and Notes}

1 A. Fujishima, X. T. Zhang, D. A. Tryk, Surf. Sci. Rep. 2008, 63, 515 .

2 M. R. Hoffmann, S. T. Martin, W. Y. Choi, D. W. Bahnemann, Chem. Rev. 1995, 95, 69.

3 B. Ohtani, B. Pal, S. Ikeda, Catal. Surv. Asia 2003, 7, 165.

4 Y. Shiraishi, T. Hirai, J. Photochem. Photobiol. C Photochem. Rev. 2008, 9, 157 .

5 Y. M. Xu, C. H. Langford, J. Phys. Chem. B 1997, 101, 3115.

6 F. Xamena, P. Calza, C. Lamberti, C. Prestipino, A. Damin, S. Bordiga, E. Pelizzetti, A. Zecchina, J. Am. Chem. Soc. 2003, 125, 2264.

7 S. Ikeda, Y. Kowata, K. Ikeue, M. Matsumura, B. Ohtani, Appl. Catal. A Gen. 2004, 265, 69.

8 K. Inumaru, T. Kasahara, M. Yasui, S. Yamanaka, Chem. Commun. 2005, 2131.

9 S. Ikeda, Y. Ikoma, H. Kobayashi, T. Harada, T. Torimoto, B. Ohtani, M. Matsumura, Chem. Commun. 2007, 3753.

10 S. Ikeda, H. Kobayashi, Y. Ikoma, T. Harada, T. Torimoto, B. Ohtani, M. Matsumura, Phys. Chem. Chem. Phys. 2007, 9, 6319.

11 P. D. Bailey, P. A. Millwood, P. D. Smith, Chem. Commun. 1998, 633.

12 C. Graf, D. L. J. Vossen, A. Imhof, A. van Blaaderen, Langmuir 2003, 19, 6693 .

13 B. Ohtani, K. Iwai, S. Nishimoto, S. Sato, J. Phys. Chem. B 1997, 101, 3349.

14 B. Pal, S. Ikeda, H. Kominami, Y. Kera, B. Ohtani, J. Catal. 2003, 217, 152.

15 B. Ohtani, E. Aoki, K. Iwai, S. Nishimoto, J. Photosci. 1994, 1, 31.

16 B. Ohtani, S. Tsuru, S. Nishimoto, T. Kagiya, K. Izawa, J. Org. Chem. 1990, 55, 5551.

17 K. C. Akratopulu, L. Vordonis, A. Lycourghiotis, J. Catal. 1988, $109,41$.

18 B. Ohtani, S. Tsuru, unpublished results.

19 L-Lysine hydrochloride was used and equimolar amount of sodium hydrochloride was added to neutralize the acid. 